\section{LES REMÈDES DE BONNE FEMME. DE LA COMPILACIÓN DE SABERES POPULARES EN LOS TRATADOS MÉDICOS FRANCESES AL DESCRÉDITO DE LA CONDICIÓN FEMENINA}

\author{
Jordi Luengo López \\ Universidad Pablo de Olavide de Sevilla \\ jluengol@upo.es
}

\begin{abstract}
Cómo citar este artículo/Citation: Luengo López, J. (2014). "Les remèdes de bonne femme. De la compilación de saberes populares en los tratados médicos franceses al descrédito de la condición femenina". Arbor, 190 (769): a170. doi: http:// dx.doi.org/10.3989/arbor.2014.769n5009
\end{abstract}

Recibido: 12 julio 2013. Aceptado: 18 enero 2014.

RESUMEN: En francés antiguo, todo remedio que probara su eficacia, se le otorgaba la designación de bonne fame. La denominada médicine usuelle hizo uso de ellos, desde la segunda mitad del XIX, hasta bien entrado el siglo XX, difundiendo la imagen de la bonne femme como una mujer ya anciana, pero colmada de sabiduría. Sin embargo, el término fue desvirtuándose progresivamente, adquiriendo un sentido peyorativo que igualmente terminaría por desacreditar a aquellas mujeres que eran portadoras de los saberes tradicionales. A través del análisis de los tratados médicos y literarios franceses, se pretende demostrar cómo la bonne femme se convertía entonces en una entrometida, una charlatana y, en última instancia, en una bruja que con su palabrería denigraba la imagen de otras mujeres. Los saberes que en un principio eran propios del mundo de la ciencia y la medicina, terminarían vinculándose al mundo de la magia y la superstición, en función de la gradual devaluación de la condición femenina.

PALABRAS CLAVE: Remèdes de bonne femme; tratados médicos franceses; imagen de las mujeres; ciencia; superstición.

\section{LES REMÈDES DE BONNE FEMME. FROM THE COMPILATION OF POPULAR WISDOM IN FRENCH MEDICAL TREATISES TO THE DISREPUTE OF THE FEMALE CONDITION}

Copyright: (C) 2014 CSIC. Este es un artículo de acceso abierto distribuido bajo los términos de la licencia Creative Commons Attribution-Non Commercial (by-nc) Spain 3.0.

ABSTRACT: In ancient France, all remedies with proven efficacy were granted the status of bonne fame. Médicine usuelle made use of these remedies from the second half of the nineteenth century to well into the twentieth century, and at the same time spread the image of the bonne femme as an extremely wise old woman. However, the term was gradually distorted, taking on a pejorative meaning that would end up discrediting the women who were the bearers of this traditional knowledge. From an analysis of the French medical treatises and literature, we aim to show how the bonne femme came to be seen as a busybody, a quack, and in the final instance, a witch who, through her gossip, denigrated the image of other women. Hence, the knowledge that initially fell within the realms of science and medicine eventually became bound up with magic and superstition, as the status of women was gradually devalued.

KEYWORDS: Remèdes de bonne femme; French medical treatises; image of women; science; superstition. 
Les bonnes femmes ont quelque fois de bons remèdes, mais il faut y prendre garde

Antoine Furetière, 1702

\section{ETIMOLOGÍA EN FEMENINO DE UN TÉRMINO MÉDICO-POPULAR}

En francés antiguo, todo remedio que probara su eficacia, se le otorgaba la designación de bonne fame, expresión que provenía del latín bona fama y que se utilizaba para designar aquello que gozaba de buena reputación. Esta asociación etimológica entre los remedios populares y, el valor positivo que la tradición y la experiencia médica les otorgaba, pese al descrédito que iría sufriendo con el tiempo, se seguiría recordando aún en pleno siglo XX. Henry de Varigny (18551934), periodista y naturalista darwinista, lo señalaba en el hoy ilocalizable periódico Savoir, que él mismo dirigió, cuando insistía en el uso de las plantas como medio para curar múltiples males y enfermedades del organismo humano. También lo recalcaba el Dr. Paul Farez (1868-1940), cuando, en 1936, publicaba, en uno de los folletines del Journal des débats politiques et littéraires (1814-1914), un breve compendio sobre las virtudes de las plantas como medicina natural donde recogía gran parte de los resultados de Varigny.

Con el transcurso de los siglos, el vocablo fame - famé(e) (afamado / reputado) terminaría siendo remplazado, debido a su pronunciación, por el de femme (mujer), cuyo origen se encontraba en el ocaso del siglo XVII. Sin embargo, ambos sentidos continuarían yendo de la mano hasta mediados de la era decimonónica, sin encontrarse, en esta comunión léxica, ninguna connotación peyorativa. Antoine Furetière (1619-1688), en 1702, en su Dictionnaire Universel, subrayaría el uso que se había dado a este término al indicar cómo del viejo nombre fame $^{1}$, se había pasado al adjetivo famé(e), pudiéndose emplear en un sentido positivo, pero también negativo (infame, infamie o diffamer). Bonne femme seguirá, por lo tanto, una evolución paralela al de fame, en la cual nunca se dejará de relacionar dicho término con los sabios conocimientos ancestrales y su consecuente utilización por parte de las mujeres.

Con todo, el término bonne femme, a nivel terminológico, continuó siendo un misterio, ya que sus interpretaciones eran múltiples y nunca demasiado precisas. Maurice Spronck (1861-1921), político francés y crítico literario, coincidía con esta aseveración al resaltar el enigmático sentido del vocablo compuesto ante el hecho de ver incoherente que una mujer de
Poitiers, a quien se le concedía el distintivo de bonne femme, contribuyera con una considerable suma de dinero a la campaña de M. Bazille, diputado radical de Viena, el cual aspiraba a convertirse en Ministro:

Faut-il prendre le mot " bonne femme » dans une acception figurée et peu usitée, dont le sens nous échappe ? Les dictionnaires de la langue française sont muets sur ce chapitre. Littré ${ }^{2}$ parle de " contes de bonne femme », de " remèdes de bonne femme »; il existe aussi d'autre part, je crois, un « potage à la bonne femme ». Mais, ça n'est évidemment pas ça (Spronck, 1896, p. 1).

Al margen del desconocimiento que había en torno al origen y el significado del término en cuestión, y las anécdotas que pudieran surgir, a la mujer que servía de abanderado a dicho concepto se le concedía cierto halo de sabiduría, solo aprehensible con la experiencia adquirida con el lento transcurso de los años. Viejas recetas, usos particulares de las plantas u otras alternativas a la Medicina tradicional, se transmitían de generación en generación, con la única garantía de que su efectividad estaba más que comprobada. Nadie buscaba el porqué de su eficacia, ni se discutía el empleo que pudiera darse a estos remedios, limitándose únicamente a recurrir a ellos cuando se necesitaban. Sin embargo, la buena fama que estos gozaban casi nunca se debía al hecho de que las mujeres que lo difundían habían recibido una buena educación, sino más bien al haber estado atentas a la herencia de la ancestral tradición pasada de generación en generación.

\section{LA EDUCACIÓN DE LA BONNE FEMME}

\subsection{La instrucción de las mujeres en el «arte de curar»: entre la Medicina oficial y la tradicional}

Hasta bien entrado el siglo XVII, momento en que empezó a popularizarse la expresión de remède de bonne femme, e incluso durante los siglos que la sucedieron, la educación de las mujeres, en líneas generales, quedaba circunscrita a las denominadas tâches ménagères (tareas del hogar), estando estas acordes con las virtudes que el imaginario colectivo otorgaba a su feminidad, es decir, las de ser hermosas, tiernas, dulces y volcadas al alterocentrismo ${ }^{3}$. No fue hasta 1687, cuando Fenelón ${ }^{4}$ (1651-1715), en su Traité de l'éducation des filles, que, al margen del juicio casi generalizado de las mentalidades de la época, se cuestionó el hecho de que las mujeres tuvieran que estar limitadas al desempeño de las labores domésticas. Según este escritor, y teólogo, la 
educación de las mujeres era tan importante como la de los hombres y, en consecuencia, debía de ser regularizada (Grell, 2004, p. 21). Sin embargo, el sentido que Fenelón daba a la educación de las mujeres era el de ser formada para "acompañar» a los hombres en todas sus ocupaciones, tanto dentro del espacio de lo privado, "satisfaciéndoles» y contribuyendo a hacer lo más grato posible su descanso, como en el de lo público, escuchando sus problemas y apoyándoles moralmente en sus resoluciones. Se trataba, pues, de continuar potenciando esa faceta alterocentrista, considerada innata en la identidad femenina, a través de la cual las mujeres procuraban entender las emociones ajenas, como pudieran ser el dolor, la angustia o el sufrimiento, pero sin mirar por las suyas propias. En ese cúmulo de obligaciones, además, estaba el deber de aliviar los dolores que pudieran surgir a sus allegados en materia de salud, valiéndose, para ello, de los remèdes de bonne femme. La bonne femme cobraba, entonces, un significado más al que añadir a la entelequia de esa "feminidad tradicional $»^{5}$ mal atribuida, pues la mujer que así procediera cumplía con las prerrogativas pautadas por el discurso dominante.

Esta fue la tónica dominante durante todo el siglo XVIII, aunque ya desde la centuria anterior, hubieron mujeres que rompieron con este modo de concebir la educación del colectivo femenino, y muy particularmente en lo atinente a la formación médica. Indudablemente fueron casos aislados, la gran mayoría de ellas provenientes de la aristocracia, pero su instrucción en distintos ámbitos del saber posibilitó que estas pudieran profundizar en otros dominios más concretos, reflexionando, así, sobre determinadas disciplinas de las que se les apartaba por razón de sexo. Una de estas transgresoras a la norma establecida fue Madame de Sévigné6 (16261696), quien, a través de su obra Lettres de Madame de Sévigné (1635-1696), no solo mostraba ser una mujer bien instruida en distintos campos del conocimiento, sino que también daba su opinión acerca de la Medicina oficial y aquella proveniente de la tradición. La marquesa mostraba, como lo hacía un contemporáneo Molière ${ }^{7}$ (1622-1673), una confianza muy limitada en la ciencia médica, siendo, por lo tanto, mucho más partidaria de la Medicina popular ${ }^{8}$ y los denominados remèdes de bonne femme (Pauliquen, 2006, p. 12). La importancia que Marie de Sévigné daba a esta última, así como el recopilatorio de remèdes que ocasionalmente hizo en su obra, llevó a que, incluso en pleno siglo XX, se siguiera reconociendo su labor ${ }^{9}$.
Ya en la Segunda República, empezó a oficializarse la educación de niñas y señoritas, gracias a la implantación de la ley Duruy (1867), donde se establecía la instauración de una École de filles en cada comuna de más de 500 habitantes, y de la ley Camille Sée (1880), con la que la educación secundaria se abría también a las mujeres, aunque los planes educativos eran distintos para cada uno de los sexos, no siendo estos comunes hasta 1925. En 1881, ya con la Tercera República, se crean las Écoles maternelles, en cuyo seno la educación para las niñas era gratuita y laica, pero no obligatoria ${ }^{10}$. Durante todo este tiempo, los programas ideados para las mujeres seguían centrándose en el aprendizaje de todo lo atinente a los quehaceres domésticos y a la puericultura. En relación a este último aspecto, ante los altos índices de mortalidad infantil ${ }^{11}$, en los albores de la pasada centuria, se crearían las Écoles de Mères donde se enseñaba a las jóvenes a ser buenas madres y a ocuparse correctamente de sus futuros bebés. Jean Frollo, seudónimo utilizado por el político republicano radical Charles-Ange Laisant (18411920), en Le Petit Parisien (1876-1944), informaba sobre la importancia de la implantación de estas escuelas recalcando que eran muchas las mujeres que no sabían nutrir a sus bebés, satisfacer todas sus necesidades, ni curarlos adecuadamente, pues, para ello, recurrían con frecuencia a los remèdes de bonne femme (Frollo, 1904, p. 1). Sin embargo, pese a los esfuerzos realizados en estos centros, y las nociones que sobre Medicina oficial se inculcaban en sus aulas, así como las campañas difundidas por la prensa, la Medicina tradicional transmitida de madres a hijas, sobre todo entre las capas más humildes de la población, seguía siendo una constante en el quehacer cotidiano del colectivo femenino. Esta evidencia la corroboraba el periódico católico La Croix (1880-), quien, en 1919, quince años más tarde de la exhortación de Laisant, seguía denunciando el modo en que las madres recurrían al uso de los remèdes de bonne femme, así como a otras sustancias consideradas tóxicas para los neonatos ${ }^{12}$, como la cocaína o los antisépticos (G. P., 1919b, p. 3). Sin duda, resulta significativo que la prensa se uniera en esta cruzada contra los remèdes de bonne femme, cuando, apenas unas décadas antes, presentaba estos remedios como parte integrante de la «economía doméstica» que toda mujer debía de seguir ${ }^{13}$.

Pocos años después, en 1922, las mujeres consiguieron entrar en la Universidad con los mismos derechos que los hombres, ya que hasta el momento no se les otorgaba el estatus de oficialidad a las disciplinas 
que en sus aulas pudieran cursar ${ }^{14}$. Hubo, no obstante, algunos precedentes en los estudios de la Ciencia Médica, siendo el ejemplo más representativo el de Madeleine Brès (1839-1925), primera mujer francesa inscrita en la Facultad de Medicina y convertida en doctora en 1875, aunque la regla general era la de reservar estos conocimientos al colectivo masculino. Con todo, también existieron mujeres que supieron aunar las enseñanzas oficiales a las que difícilmente podían acceder, y que aprendían de forma autodidacta, con los remèdes de bonne femme que se les atribuía por razón de sexo.

\subsection{Los remèdes de bonne femme d'Arthème Fayard}

Uno de los más significativos reconocimientos otorgados a esa bonne femme que supo integrar la ciencia con la tradición, sin duda, lo encontramos en la presentación que los hermanos editores Fayard hicieron de una autora anónima de cierta obra publicada bajo el título de Les Remèdes de la bonne femme, encyclopédie générale d'hygiène et de médicine usuelle, aparecida en París, entre 1895 y 1897. En el prefacio de la obra, los editores señalaban que «Madeleine D...» había sido durante toda su vida conocida con la acepción de bonne dame, pero tras haber pasado veinte años de su vida dedicada a la elaboración de este manual, y con una edad ya avanzada, se merecía recibir la designación de bonne femme. La desconocida Madeleine, hija de un oficial muerto en el campo de batalla, fue enfermera en la contienda bélica franco-prusiana de 1870-1871. Tras volver de la guerra, se prometió con un joven estudiante de Medicina de Estrasburgo, de donde ella era también natural, pero este falleció al concluir sus exámenes de final de carrera. Poco después, la joven pasó a ser institutriz en el castillo del igualmente anónimo Marqués de G..., en Amiens, donde continuó de manera autodidacta con los estudios de su difunto novio hasta terminar de escribir el manuscrito.

Este libro no era la obra de un médico, si bien advertimos que en su redacción no se apreciaban los tecnicismos que solían utilizarse en los manuales de la época. Su principal característica era que estaba escrito en un lenguaje coloquial, próximo al público lector y comprensible para todo el mundo. En él, se podían encontrar todo tipo de consejos para cualquier edad y, siempre expresados de un modo claro y sencillo. Se trataba de un auténtico compendio de higiene preventiva, un prontuario de cómo curar las heridas en el campo de batalla ${ }^{15}$, y donde se distinguían numerosos consejos destinados a las mujeres, sobre cómo ser una buena madre ${ }^{16} \mathrm{y}$ aprender a reaccionar de forma inteligente ante cualquier problema o enfermedad que pudiera surgirles, en cuanto a lo que se refería a ellas mismas como sujetos a tratar ${ }^{17}$, pero también a sus hijos y, en especial, a sus hijas.

\section{BONA FAMA PARA LOS REMÈDES DE BONNE FEMME}

\subsection{Tres siglos de esplendor para los remèdes de bonne femme}

El interesante manual de Madeleine D. nos demuestra que los remèdes de bonne femme fueron bien recibidos hasta finales del siglo XIX, aunque sus virtudes se siguieron cantando hasta bien entrada la pasada centuria. De hecho, esta bona fama empezó apenas una década antes de que Furetière la mencionara, en 1693, con el texto Histoire du cardinal Ximenès (1693) del Dr. Valentin Esprit Fléchier (1632-1710), obispo de Nîmes, donde se sugería a los médicos de abstenerse de lanzar calumnias contra los remèdes de bonne femme, sobre todo cuando la efectividad de estos estaba más que demostrada. Un lustro más tarde, sería el Dr. Michael Ettmüller (1644-1683) (1698, p. 322), en su obra Pratique spéciale de médecine, aparecida en 1698 , quien reconocería las cualidades de algunos remèdes, como, por ejemplo, el del consumo de vino tibio para aquellas mujeres que tras el parto quisieran volver a dar a luz. A esta tendencia, ya en el siglo XVIII, se le sumaba el estudio de Laurent Le Conte (16?-1733) titulado La Médicine des pauvres, publicado en 1736 , donde se comenta que los remèdes de bonne femme eran mucho mejor que numerosas soluciones médicas (Boylesve, 1909, p. 1). Cuéntese también con la aportación del Dr. Jacques Cristoph Valmont de Bomare (1731-1807) (1768, p. 678), quien, en 1768, en su obra Dictionnaire raisonné universel d'histoire naturelle, elogiaba la efectividad de un remède de bonne femme para evitar que los niños se orinaran en la cama. Asimismo, el Dr. Charles-Marie de la Condamine (1701-1774) (1754-1758, pp. 50-51), en su obra Mémoires sur l'inoculation de la petite vérole, escrita entre 1754 y 1758, felicitaba también la conducta del Dr. M. Hecquet por haber tomado la determinación de investigar la eficacia de aquellos vinculados a la sífilis.

La tónica continuaría un siglo más tarde, siendo clara muestra de ello el juicio emitido por el Dr. Jules Massé (1825-1899) (1861, p. 124), el cual, en su Encyclopédie de la Santé, fechada en 1861, ensalzaba también estos remedios, aludiendo, en esta ocasión, 
al caso de su buena aplicación en la epilepsia, lo que le llevaba a aconsejar a los médicos que no prohibieran aquello que realmente funcionaba. Tres años antes, el Dr. André Lebel (1858, p. 144) había hecho lo mismo con las hemorroides, en su obra Monographie des Hémorrhoïdes ou Traité pratique de ces Maladies, al apuntar lo virtuosos que eran algunos remèdes de bonne femme para curar esta dolencia. De igual modo, algo más de dos décadas después, en 1879, un ingeniero de minas de Nancy llamado M. Braconnier, escribía un tratado sobre la eau verte (agua verde), la cual poseía una gran densidad de microalgas que resultaban ser muy buenas para las enfermedades de los ojos (Parville, 1879, p. 2). Todos estos compendios eran leídos, y seguidos, por las capas instruidas de la población, generalmente la aristocracia y la alta burguesía ${ }^{18}$, pero no diferían demasiado de los que, en las esferas humildes, seguían estando presentes en la cotidianidad de sus días.

\subsection{Los remèdes de bonne femme en el seno de la Modernidad}

En la segunda mitad de la era decimonónica, en 1863, el escritor popular francés Ponson du Terrail ${ }^{19}$ (1829-1871) (1863, p. 1), en el periódico Le Petit Journal (1863-1944), hablaba de un tiempo donde la gente confiaba en los remèdes de bonne femme, dando por hecho que en aquel entonces la Medicina tradicional ya no estaba en boga. Sin embargo, al iniciarse la pasada centuria, si bien el maestro del roman-feuilleton estaba en lo cierto, como se ha podido comprobar en apartados anteriores, los remèdes de bonne femme volvieron a ser una referencia en el "arte de curar». Esta evidencia puede constatarse no solo en los tratados médicos que vieron la luz en los albores del pasado siglo, sino también en la literatura no-científica y en la prensa cotidiana.

Los muchos prejuicios que recaían ${ }^{20}$ sobre los remèdes se disiparon a medida que se les fue otorgando cierto criterio de cientificidad, el cual se fundamentaba en el hecho de que estos provenían del uso de las plantas como remedios naturales. Ya en 1890, Louis Noir, seudónimo del periodista Victor Noir ${ }^{21}$ (1848-1870), en el epílogo de Au village, relato publicado por entregas en el diario conservador Le Matin (1833-1944), mencionaba a una mujer llamada mère Briquet, quien solía adentrarse en el bosque para encontrar las plantas oportunas para curar todo tipo de enfermedades, además de tener instalada en su hogar una biblioteca botánica y una despensa al uso. Aun tratándose de un relato de fic- ción, la opinión del periodista francés era compartida por gran parte del imaginario colectivo, aunque la Médecine Végétale no se reconocería como complemento - ni mucho menos como sustituto- de la Medicina oficial hasta bien entrado el siglo $\mathrm{XX}^{22}$. Los remèdes de bonne femme poseían la misma composición que muchas de las sustancias químicas obtenidas a través de medios artificiales, siendo, además, sus efectos sobre el organismo mucho más suaves que los causados por fármacos y medicinas ${ }^{23}$.

En lo atinente a los tratados médicos, sin duda, el que gozó de mayor popularidad fue el publicado, en 1907, por los doctores Augustin Cabanès (18621928) y Jean Barraud, cuyo título fue el de Comment on se soigne aujourd'hui. Remèdes de bonne femme. Dicha obra era la continuación de Comment se soignaient nos pères. Remèdes d'autrefois, la cual había sido redactada por el Dr. Cabanès en solitario en 1905 (Anónimo, 1906²4, p. 1). El estudio en cuestión demostraba que la ciencia médica había tomado mucho prestado del saber popular, siendo, a su vez, un compendio de varios remedios donde se probaba esta evidencia. Ambos doctores quisieron iniciar el avant-propos de su estudio con unas palabras de la obra del Dr. Julien Noir, De quelques préjuges, superstitions, sanctuaires et pèlerinages, etc.; essai de folk-lore médical, publicado por el Progrès médicale en 1905, las cuales creían perfectas para ser la antesala de lo que a continuación expondrían:

L'étude méthodique des superstitions, des préjuges relatifs à l'art de guérir, mériterait mieux que la publication de notes sans doute fort nombreuses et fort savantes, mais qui sont dispersés un peu par tout. À notre époque où les sociétés de tous genres pullulent, souvent sans but bien déterminé, il y a lien de s'étonner qu'une société de folk-lore médical n'ait pas été fondée; ses travaux dépasseraient en originalité, et souvent en intérêt, ceux de bien des Sociétés médicales réputées (Cabanès y Barraud, 1907, p. 1).

Ese era precisamente el propósito de los doctores Cabanès y Barraud, dotar de un sólido criterio de cientificidad a la Medicina tradicional, siendo esta de igual modo considerada que la Medicina oficial por las sociedades médicas.

En ese mismo año de 1907, en Marsella, el Dr. Francis Aurigo publicaba la obra Fégatothérapie, méthode vivante enseignée par les lois de la nature, donde también se abogaba por la utilización de los remèdes de bonne femme. Aurigo consideraba que todos aquellos productos provenientes de la deno- 
minada Medicina oficial, siendo en su mayoría compuestos químicos obtenidos en el laboratorio, eran resultado directo de un méthode morte. El propio Dr. Cabanès presentaba este volumen en Le Petit Parisien coincidiendo con el criterio del doctor marsellés, señalando, además, que, pese a que el ser humano se empecinara en imitar a la naturaleza, este siempre terminaría por ceder a su magnificencia: "À mesure que I'humanité avance en âge, écrit-il, I'homme, qu'on veuille ou non, sera de plus en plus porté à imiter la nature; or, la nature est une végétation progressive vivante, par conséquent, l'homme mettra de côté toutes les œuvres de mort, pour ne plus penser qu'à des œuvres de vie» (Cabanès, 1910, p. 1). La Medicina tradicional adquiría, así, un valor añadido al que pudiera atribuírsele por sus cualidades curativas, pues recurrir a ella era apostar por la vida en su extensión.

Esta evidencia se afianzaría en las décadas siguientes, consolidándose en la obra Près d'eux (1938) de Henry Goudard, cuyo prólogo fue realizado por el célebre académico de la lengua francesa Henry Bordeaux (1870-1963), donde se indicaba que ciertos remedios populares podían ser muy beneficiosos para la salud de quienes los ingerían. Louis Brunet (1847-1905), político francés de profesión periodista, anunciaba este libro en el periódico católico $L a$ Croix, subrayando que la intención de Goudard era la de reafirmar en la juventud francesa el amor por la tierra de la que era oriunda, sin olvidar, por ello, la importancia de todo aquello que esta ofrecía para la salud del cuerpo y del alma. Goudard, aprovechando la entrevista que le hacía Brunet, se aferraba a esta idea exponiendo las cualidades de algunos remèdes de bonne femme, que, si bien no eran del todo efectivos, al menos ayudaban a paliar el dolor o ralentizar el avance de la enfermedad. Entre los muchos que se exponían, se encontraba, por ejemplo, el de aplicarse sobre el pecho carne cruda para evitar la propagación del cáncer de mama:

... beaucoup son le fruit de l'empirisme et de l'observation. Entre autres, l'application de viande crue sur les cancers du sein. On " nourrit le cancer ». Effectivement, l'évolution devient d'une lenteur étonnante. Ce procédé thérapeutique serait très scientifique puisque ce sérum apporté par le muscle agirait par ses lipoïdes, inhibiteurs de la croissance cellulaire... (Brunet, 1939, p. 7).

En cualquier caso, aunque eventualmente se reconociera el poder de curación de la Medicina tradicional, en el ámbito periodístico y en distintos tratados médicos, casi siempre inducidos a ello por los evidentes efectos beneficiosos de las plantas, lo cierto es que, a medida que se iba avanzando en el tiempo, los remèdes de bonne femme quedaron como recursos secundarios a la Medicina moderna u oficial.

\subsection{Les miettes de la science}

Al margen de los tratados recién aludidos, en la prensa cotidiana del período de entresiglos, también se promocionaron los remèdes de bonne femme en secciones especiales elaboradas con ese fin. Encontramos estas en el periódico La Croix, dentro del apartado "Recette Utile» (1891-1902), y del de "Conseil du Jour» (1888), cuyo autor, Marc de Rossiény ${ }^{25}$, también reproducía esta última sección en Le Gaulois; además, este mismo periódico, sin variar demasiado el título, igualmente exponía aquellos remedios populares en las secciones «Un Conseil par Jour» (1879-1881) ${ }^{26}$, redactado por un desconocido Jean de Bay"27, y "Le Conseil Quotidien» (1889), a cargo de Octave Sully ${ }^{28}$. En otros casos, la prensa introducía los remèdes en secciones reservadas a cuestiones científicas, como ocurría en La Croix con el apartado "Causerie Scientifique» (1885-1943) del seudónimo Somsoc, o dentro de las "Variétés», como se daba el caso en la publicación infantil Le Petit Français Illustré (1889-1905), en la que se ofrecían algunas soluciones para el dolor de garganta, las quemaduras, la fiebre cerebral y tifoidea, para parar el sangrado y el hipo (Anónimo, 1902 , p. 215). Sin embargo, en ninguna de estas iniciativas se vinculaba estos recursos originarios de Medicina popular con la figura de la bonne femme o con el colectivo femenino en general.

Años más tarde, no obstante, Le Petit Parisien, desde abril de 1913 hasta marzo de 1914 aproximadamente, presentó estos remedios dentro de un apartado denominado "Les miettes de la science» (Las migas de la ciencia), donde una mujer, Émilie Gautier, redactora de la publicación parisina, insistía en los múltiples usos que podía dársele a las plantas para curar todo tipo de dolores, males y enfermedades: la hidropesía, la albuminuria, el dolor de pies y piernas, entre otros. En esta misma sección también se hallaban otros temas relacionados con la ciencia, como era el uso de la electricidad, el radio ${ }^{29}$ industrial, las proteínas en el organismo humano, la composición de la sangre, entre otros de análogo interés. Aquí, los remèdes de bonne femme eran anunciados por una mujer, quien, además de difundir el saber que el discurso dominante supeditaba 
a las integrantes de su sexo, demostraba ser conocedora de otras curiosidades científicas, cuya exposición generalmente se reservaba a los hombres. El hecho de que Le Petit Parisien optara por conceder mayor protagonismo a las mujeres en una de sus secciones, sin duda, era un claro signo de progreso, pero, sin embargo, tras esta breve campaña, la estrategia no se repetiría hasta casi bien pasadas tres décadas. Así, en 1942, el periódico parisino volvería a dar paso a la Medicina tradicional en otra de sus secciones, "Bons Remèdes de Bonne Femme», atribuyéndosela de nuevo a otra mujer, Françoise Cordier, aunque, en esta ocasión, los remèdes de bonne femme se anunciaban como parte integrante de otros temas considerados propios de la antes aludida «economía doméstica» y a la higiene femenina.

\section{DESCRÉDITO A LOS CONSEJOS DE LA BONNE FEMME}

\subsection{Los males de los remèdes de bonne femme}

Con todo, y a pesar de las buenas referencias que se hacían en algunos manuales médicos y en el mundo periodístico, lo cierto es que, desde mediados del siglo XVIII, estos elogios habían dejado de lanzarse de modo unánime. La falta de crédito hacia los remèdes de bonne femme iba reiterándose a lo largo de los siglos, cobrando cada vez más fuerza con los avances médicos, aunque, a la par, también continuaban recibiendo alabanzas. Los detractores de los remèdes se basaban en el hecho de que aquellos remedios que eran transmitidos por las mujeres de forma oral, sobre todo teniendo en cuenta que la gran mayoría de estas eran incultas e iletradas, no podían tener fiabilidad científica alguna.

Con cierta profusión, en el ocaso de la era decimonónica, se difundía el dicho popular de que los mejunjes tradicionales, si bien no curaban las enfermedades para las que se aplicaban, al menos, no hacían mal alguno a quien los ingería: «si ça ne vous fait pas de bien, au moins ça ne vous fera pas de mal» (Anónimo, 1892, p. 2; Ciseaux, 1880, p. 3). En esa misma época, sin embargo, no eran pocos los testimonios que aseguraban todo lo contario. Se constataba este hecho en Le Petit Parisien, dentro de la sección de noticias atinentes a los casos llevados hasta los tribunales, al informarse sobre cómo una mujer llamada Mme Béatrix Lagande dio un remedio casero a su vecina, Mme Émilie L., para que cicatrizara pronto de un corte que se había hecho en la mano, resultando, empero, contraproducente al infectársele la herida y tener que ser ingresada en el hospital en estado de suma gravedad (Anónimo, 1897, p. 3). Mme Lagande, si bien su intención nunca fue la de dañar a su vecina, lo cierto es que, bien por ignorancia o por una desmesurada fe en las recetas populares, terminó por agravar el mal de su congénere.

Apenas una década más tarde de este suceso, en este mismo periódico, el Dr. Paul Strauss (1906, p. 4), en un artículo sobre higiene y asistencia médica, recalcaba que la aplicación de los denominados remèdes de bonne femme había sido fatal para algunos enfermos, cuyo mal se hubiera podido curar con un tratamiento adecuado a base de medicinas modernas cuando todavía se estaba a tiempo. Sin embargo, como se ha podido constatar en el apartado anterior, no siempre estos remedios eran nocivos para quienes a ellos recurrían, ni tampoco las mujeres que los recomendaban estaban alejadas por completo de la verdad de su uso medicinal, pero confiar ciegamente en ellos, y tomarlos como única curación posible, sin duda, era un craso error.

\subsection{De su vilipendio en la literatura no-científica}

En lo referente a la literatura ajena al mundo de la ciencia, los remedios tradicionales gozaron de relativa buena fama hasta finales del siglo XIX, momento en que los avances de la Medicina moderna empezaron a quebrar la confianza que el imaginario colectivo había depositado en ellos. Generalmente, cuando la Medicina popular hacía su irrupción en la literatura era siempre de la mano de una mujer que daba inmediata solución a aquello que la ciencia médica oficial no había podido resolver. Constatamos esta evidencia en Le Comte de Guiche ${ }^{30}$ de Mme Sophie Gay (1776-1852), obra publicada por entregas en el periódico La Presse (1836-1928), donde, en uno de los pasajes, se cuenta cómo una joven había conseguido curar a un sargento herido de bala con un remède de bonne femme (Gay, 1844, p. 5). A. de Corbetton (1897, p. 3), colaborador de La Croix, algunas décadas más tarde, en una obra por entregas publicada a modo de folletín, cuyo título era el de Chez les autres, hablaba de una niñera llamada Nanette, quien, con la ayuda de un remède, cura a uno de los niños que tenía a su cargo, André, bajo el estupor de los «hommes de l'art» de la Medicina.

Con todo, y a pesar de ese latente vínculo entre la Medicina tradicional y el colectivo femenino, en circunstancias muy concretas, también los hombres contribuían a la difusión de este saber popular. Así, en 1819, en el Journal des débats politiques et 
littéraires, el geógrafo danés-francés Conrad MalteBrun (1755-1826) contaba la anécdota de que el rey de Prusia Federico II el Grande (1712-1786), sufría de un panadizo ${ }^{31}$ agudo (mal d'aventure, en francés), un dolor insoportable cuya cura ni siquiera los más reputados médicos de la Facultad de Medicina de Berlín habían podido dar con ella. Sería un granadero, un soldado de infantería cargado con granadas de mano de nombre Frank, quien, gracias a un remède de bonne femme, lograría erradicar el mal del rey. Este, a cambio, le pidió la nariz de un usurero judío, pues creía que con ella podría conquistar el corazón de la sirvienta del monarca (Malte-Brun, 1819, pp. 1-3). Dicho relato, real o imaginado, sirvió para que el dramaturgo René Perrin escribiera su tragedia Hécube, la cual fue representada, en 1819, con gran éxito en el Théâtre Français. Además, al margen del breve clamor popular que tuvo dicha historia - pues apenas fueron unos meses lo que este duró-, trasciende el hecho de que en tiempos de guerra los hombres también recurrieran a estos remedios como alternativa a la falta de medicamentos, valiéndose, para ello, y muy frecuentemente, de las plantas naturales. Con todo, la tónica que se siguió desde el ocaso finales del período decimonónico, acorde esta con los avances de la ciencia médica, fue la de vilipendiar los denominados remèdes de bonne femme por la poca base científica que estos tenían.

En 1896, año en que aparecía la voluminosa obra Les Remèdes de la bonne femme de Arthème Fayard, a modo de burla, un desconocido Dr. Garrulus, en su obra Les gaietés de la médicine, reproducía un diálogo entre dos interlocutores, donde uno de ellos mostraba no tener pelos en la lengua (une langue pelée, en francés), sugiriéndole el segundo mantenerla dentro de la boca el máximo tiempo posible, si bien quería curarse pronto (Garrulus, 1896, p. 171). Este último concluía el diálogo subrayando a su compañero que su efectividad estaba demostrada, porque se trataba de un remède de bonne femme $y$, en consecuencia, reconocido por la ciencia médica. Obviamente, tras este fragmento, más bien literario que científico, se dejaba entrever el descrédito que este tipo de consejos tenía ya de por sí. Décadas antes, en 1817, Pierre-Marie Quitard recordaba el dicho de "bonne femme, mauvaise tête», cuyas palabras habían sido pronunciadas por Jean Nevizan (-1540), un profesor de Derecho de Turín, quien, ya en el siglo XVI, en su obra escrita en latín Sylva nuptialis, cuya traducción en francés era la de La Forêt nuptiale, afirmaba que si bien las mujeres eran dul- ces y amables en todas sus facetas y partes de su anatomía, refiriéndose a la acepción literal de bonne femme, en lo que respectaba a "la cabeza», la razón y la inteligencia, esta era completamente nula ${ }^{32}$ (Quitard, 1817, p. 375). Los remèdes se repudiaban con ardor por el hecho de que estos provenían de aquellas mujeres que por regla general carecían de criterio científico, entre otros motivos, porque no habían sido educadas para poseerlo.

La literatura no-científica, por lo tanto, al hacer referencia a los remèdes de bonne femme, también entraba en esa tónica de desprestigiarlos. M. Théodore Leclerq procedía de este modo en una de sus piezas teatrales titulada "L'intrigant malencontreux», dentro de su obra Proverbes dramatiques, escrita entre 1827 y 1828, donde reproducía un diálogo entre un cirujano y su paciente, M. Mitis. En este encuentro imaginario, el doctor comentaba que en aquel tiempo se curaba con todo menos con la ciencia, pidiéndole a su enfermo que volviera a la consulta al día siguiente con un remède de bonne femme (Leclerq, 1827-1828, pp. 25-26). Se daba a entender que, viendo lo poco seria se había vuelto la ciencia médica, al dar crédito a este tipo de consejos, se suponía que estos también podían funcionar ${ }^{33}$, aunque en ningún momento hemos de olvidar que tal aseveración estaba formulada a modo de chanza.

Otra escena de análogas características es la reproducida por Pigault-Lebrun, en cuya obra titulada La folie française, une macédonie, contaba la historia de cómo un hombre acudía al médico con muchos dolores, dándole este un brebaje para que se remitiera de todos ellos, pero, al probarlo, el paciente respondía al médico que lo que le había dado no era más que un remède de bonne femme, pues no servía para nada y, encima, tenía muy mal gusto: "Aïe ! aïe !... Je n'y tiens pas !... C'est un supplice épouvantable... Quel remède infernal m'avez-vous mis là ? C'est un remède de bonne femme, un remède tout à fait innocent, du vinagre, du sel et du poivre. - Que le diable te confonde, empirique effronté !» (PigaultLebrun, 1880, pp. 50-51). El enfermo reprochaba al médico su poca profesionalidad al haber recurrido a estas alternativas para intentar curarle ${ }^{34}$, pues, según el paciente, estos no tenían base científica alguna.

Ya en el siglo XX, las obras donde se restaba crédito a los remèdes de bonne femme se multiplicaron, siendo algunas de ellas La Naufragée (1903) de Paul Bertnay (1846-1928), publicada por entregas en Le Petit Parisien, donde se critica a aquellos que caían fácilmente en el uso de las recetas populares; 
Le Passeur de la Moselle (1906), escrito por Jean Gauthier e igualmente publicado a modo de folletín en el periódico parisino, en cuyo texto se habla de quienes pierden el tiempo recurriendo a todo tipo de ungüento tradicional, dejando de lado a la Medicina oficial; Le Satyre del escritor belga Roger Avermaete (1893-1988) (1925, p. 3), quien, en este relato publicado por entregas en L'Humanité (1904), comentaba cómo el Dr. Ceuster, un cirujano de renombre, mezclaba la ciencia médica con algunos remèdes de bonne femme, no viendo, empero, el autor, esta práctica como algo que dignificara su reputación; o, Les mousquetaires des halles, aparecida décadas más tarde, en 1935, también en Le Petit Parisien, en la que Maurice Renard (1875-1939) comenta cómo los médicos se burlaban de los remèdes de bonne femme. Alusiones dadas a la Medicina tradicional que anunciaban, y reafirmaban, el paulatino cambio de juicio de valor que sobre los remedios populares se estaba generando, y fue aconteciendo, a lo largo de los siglos.

\section{LA BONNE FEMME: CONSEJERA DE VIDA Y SABIA EN EXPERIENCIA}

Desde finales del siglo XIX, como demuestra el caso de la autora anónima de Les Remèdes de la bonne femme, "Madeleine D...», a la bonne femme se la conocía por ser una mujer que por su larga experiencia de vida podía aconsejar, no solo sobre remedios médicos, sino también en torno al proceder y a la actitud que las jóvenes debían tomar ante cualquier dificultad o situación que les surgiera. Si estas mujeres, curtidas en la experiencia, además eran religiosas, entonces, los consejos que podía dar adquirían un doble valor. Marc de Montifaud ilustraba este caso con una breve narración titulada Une grève de femme (Una huelga de mujer), creada entre 1890 y 1891, donde una joven llamada Mlle de Lucenay, iba a ver a una supuesta Madre Superiora de un convento, quien la recibía con un gran crucifijo en el pecho y con cierta pícara malicia. Sin que la joven le expusiera el motivo de su visita, aunque adivinándolo de antemano, esta le preguntó si el hombre que le interesaba era frío, en materia de amor, para con ella o impotente en el momento de satisfacerla o «alegrarla» en un plano físico. Mlle Lucenay había acudido al convento en busca de consejo, dado que, una semana antes, su primo Raymond, quien estaba prometido a ella desde que eran niños, la había visto desnuda, pero este no reaccionó sexualmente como era de esperar. Esta actitud había inquietado a la joven, no solo porque ponía en entredicho los sentimientos y deseos que su primo pudiera sentir por ella, sino porque esta también tenía ciertas necesidades de saberse amada y deseada, y corresponder de igual modo. La Superiora le dio un remedio casero, sin que Mlle de Lucenay supiera qué había en su interior. Al volver al castillo, le pidió a Raymond que se tomara el brebaje para ver si conseguía estimularse al estar frente a sus encantos, recalcándole que el remède de bonne femme venía de una religiosa, y aunque el joven se negó en un primer momento, al proceder este de una bonne femme que además era monja, terminó por aceptar ingerirlo (Montifaud, 1890-1891, pp. 302-303). En este pasaje puede observarse cómo la efectividad del brebaje estaba asegurada, más que por la Medicina, por la propia Religión. Este último factor, aunque en Francia no tuviera tanta fuerza como pudiera ser el caso de España ${ }^{35}$, en incontables ocasiones, su credibilidad resultaba ser casi la misma cuando se trataba de mujeres que carecían de un mínimo de educación ${ }^{36}$.

Así pues, la devoción clerical que las mujeres sentían era uno de los componentes de mayor significación en el que se amparaban para definir su propia condición femenina, la cual se encontraba pautada por las consignas del patriarcado. Si una mujer no cumplía con los preceptos dictaminados por el discurso dominante, entonces, como apuntaba el refrán bien conocido en el ocaso del período decimonónico, no había solución para ellas: «il n’y a malheureusement de remèdes de bonne femme pour les mauvaises» (Un anonyme, 1892, p. 1). Los remèdes de bonne femme, por lo tanto, se concebían también como consejos de vida dirigidos a aquellas mujeres que necesitaban de guía para no apartarse del camino trazado por las mentalidades biempensantes, los cuales se les negaba a las que de este se distanciaban por voluntad propia. A dicha sentencia, también recurría el multifacético escritor, jurista y profesor de Derecho, René Bazin (1853-1932) (1893, pp. 2-3), quien, reflexionando sobre lo que denominaba société savante, denunciaba el declive de costumbres, y formas, que estaba aconteciendo a finales del siglo XIX frente a lo que había sido el primer tercio e inicios del segundo de este, donde, según el autor, las mujeres habían jugado un rol predominante -entiéndase que se habla de las pertenecientes a la alta burguesía. Bazin habla de mujeres que leían, y que no se avergonzaban de ello, ni eran vistas con malos ojos por quienes las contemplaban desempeñar dicha actividad, poniendo en entredicho lo que la tradición consuetudinaria había establecido, inclusive en lo atinente al uso de los remedios populares, 
dando así paso a la reflexión sobre su eficacidad. En este sentido, las mujeres mauvaises (malas) eran quienes se apartaban de la confianza ciega que el imaginario colectivo depositaba en los remèdes de bonne femme, porque estas, al menos, se permitían un breve instante para dudar sobre su efectividad y el porqué de su uso, algo que estaba prohibido por el discurso dominante.

A medida que se fue avanzando en la pasada centuria, como se ha podido observar, los remèdes de bonne femme perdieron gran parte de la credibilidad que poseían antaño, y no solo desde un punto de vista médico, sino porque tampoco se los tenía en consideración a pesar de la fiabilidad que les había otorgado la tradición. Da fe de ello el verso del poeta maldito Tristan Corbière (1845-1875), aparecido en su poema "La rapsode foraine et le pardon de Sainte-Anne» recogido en su obra Les Amours jaunes (1873), donde podía leerse lo siguiente: "Prête ta douce et chaste flamme / Aux chrétiens qui sont ici... / Ton remède de bonne femme / Pour les bêtes-à-corne aussi» (2003, s.p.). En este verso, recuperado por el también poeta Laurent Tailhade (1854-1919) (1902, p. 1) para el periódico L'Aurore (1897-1914), se daba a entender que todo consejo que recibiera cualquier mujer casta en materia de amor y/o sexo, en realidad, más que mejorarla, contribuía a empeorar la situación en la que se veía envuelta. Se sobrentiende, además, que tan buenas eran estas indicaciones para las mujeres recatadas que para los maridos y novios engañados, pues unas y otros eran víctimas de su propia inocencia. Aquí, sin duda, entraba en juego la educación en materia sexual, la cual, hasta bien entrado el siglo XX, no recibió la importancia que merecía ${ }^{37}$.

\section{DE LA AGUDEZA DE LOS REMÈDES DE BONNE FEMME AL NOCIVO CHISMORREO DE LA VIEILLE SORCIÈRE}

Como se ha indicado con anterioridad, el término bonne femme fue desvirtuándose progresivamente, adquiriendo así un marcado sentido peyorativo. A la bonne femme ya no se la concebía como una anciana entrañable que, con sus consejos, mezcla de ciencia y tradición, ofrecía una alternativa de curación a quien la solicitaba, sino que ocurría más bien lo contrario. La bonne femme se había convertido en una entrometida, una charlatana y, en última instancia, en una bruja que con su palabrería denigraba la imagen de aquellas otras mujeres que estaban en su punto de mira. Su saber ancestral no la salvaba del vilipendio del imaginario colectivo, que, imbuido por el discurso dominante, justificaba esta dañina actitud aludiendo al hecho de que estas no dejaban de ser mujeres. La nueva identidad atribuida a la bonne femme se extrapolaba así a todo el colectivo femenino, justificándose esta por el elevado índice de analfabetismo que existía entre sus componentes.

En 1931, una publicidad de Paris-Pastilles, medicamento que se anunciaba en Le Petit Parisien con el subtítulo de «Soyez de votre siècle», exhortaba al público lector a desconfiar de las commères (alcahuetas) que con sus habladurías difundían remèdes de bonne femme que no servían para nada, soliviantándolo, a su vez, a que comprara en la farmacia su producto. Al parecer, ampararse en los remedios populares había quedado démodé, y aunque estos estaban presentes en las "habladurías de viejas", su uso desprestigiaba a todo aquel que a ellos recurría precisamente porque asimilaba su persona a dichas chismosas comadres. Además, aunque cada región tenía sus propias panaceas para curar males y enfermedades ${ }^{38}$, en París y en el resto de regiones de provincia, este fenómeno se repetía por igual. Así, de nuevo el Dr. Francis Aurigo, en su ya citada Fégatothérapie, méthode vivante enseignée par les lois de la nature, indicaba que, en los suburbios de Marsella, las commères eran quienes curaban a los enfermos con remèdes de bonne femme (Cabanès, 1910, p. 1). Curiosamente, la utilización de estos remedios se focalizaba en las clases más humildes, y carentes de estudios básicos, de la población, donde la vida en común aunaba a sus integrantes en corrillos de barrio.

Los avances de la Medicina a principios de la pasada centuria, no habían sido lo suficientemente grandes como para remediar todas las enfermedades entonces existentes, por lo que, cuando los medicamentos no curaban al enfermo, los remèdes de bonne femme eran el único recurso al que acudir. El Dr. George Daremberg (1850-1906) (1874, p. 3), en el Journal des débats politiques et littéraires, se sorprendía de ver cómo cuando la gente se aplicaba indistintamente los remedios populares y los medicamentos requeridos para un mal concreto, siempre se atribuía su recuperación al primero de ellos. Daremberg justificaba este proceder porque el imaginario colectivo siempre buscaba algo sobrenatural a lo que acogerse. En esa misma publicación, la historiadora y crítica literaria Arvède Barine ${ }^{39}$ (1840-1908) (1893, p. 1) matizaba la reflexión del célebre médico al apuntar que siempre había habido una Medicina-Religión y otra a la que tildaba de Medicina-atea, basada esta 
última en la ciencia, y que, en la primera de ellas, allí donde se ubicaban los remèdes de bonne femme, la magia ${ }^{40}$ ocupaba un lugar predominante. De este modo, la bonne femme pasaba a atribuírsele ciertos caracteres vinculados a la hechicería, además de una nociva palabrería que dañaba la salud y la imagen de quien tenía en su punto de mira.

Charles Baudelaire (1821-1867), ya había apuntado esta particular relación al indicar que la sorcellerie era "la capacidad de llamar a los espíritus, traer algo a la memoria o a la imaginación, mediante conjuros y sortilegios» (López Castellón, 1999, pp. 90-91). La imagen de las brujas se identificaba, pues, con la de todas aquellas mujeres que tramaban falsos testimonios acerca de otras compañeras de sexo, falseando sus vidas para terminar desacreditándolas al hacer públicas sus fantasías. Así, en los antes aludidos corros de barrio humilde, generados en los suburbios de las grandes ciudades y en la campiña, no solo se contaban las fórmulas populares de bálsamos y ungüentos, sino que, además, se murmuraba sobre el comportamiento de sus congéneres, cuando, décadas atrás, lo que brindaban las bonnes femmes eran consejos para ir por el «buen camino" - entiéndase que era el de ser buena esposa y madre- y no despertar crítica alguna.

Si bien el fin último que el discurso patrimonial reservaba a las mujeres era el matrimonio, cabe decir que los sortilegios de amor cobraban otra significación bien distinta a aquella que los cuentos y/o las leyendas populares solían concederles. En las páginas de los tratados médicos franceses donde se aludía a los remèdes de bonne femme, no se leía filtro de amor alguno, ni tampoco ningún otro mejunje de análoga índole. Con todo, es muy probable que, desde el saber popular, estas mujeres dieran algún que otro consejo a las jóvenes que requirieran de sus servicios. La "caza del marido" se convertía en una de las claves de mayor importancia en el paulatino proceso de adecuación al modelo de «perfecta casada». Además, en esa lucha sin piedad por contraer matrimonio, muchas mujeres no tenían reparo en echar mano de la murmuración o de la calumnia, si con ello conseguían deshacerse de una rival. Charles Grimaud, antiguo profesor de filosofía en el externado Des Enfants-Nantais, en su obra titulada Nonmariées, aparecida en París en 1933, advertía que este fenómeno no se limitaba a las capas más bajas de la población, sino que también atañía a las damas burguesas, quienes, a pesar de su educación, caían de igual modo en este nocivo ejercicio. De ahí que el abate Charles Grimaud advertiera a sus feligreses de los perjuicios que podían ocasionar las imaginaciones exaltadas al «darle a la sin hueso»:

Si elles seules devaient souffrir de ces fantômes, le mal serait limité. Mais quand les langues auront publié aux quatre coins des salons mondains les " histoires absolument vraies", nées du rêve de ces illusionnées, combien de personnages honorables seront blessés ? Aussi vaut-il mieux être inconnu de ces mauvaises langues, dont il est terrible même d'être l'ami (Grimaud, 1933, p. 145).

A juicio del religioso, no había ninguna mujer que en algún momento de su vida no se hubiera abocado a esta malsana distracción, dado que, pese a las tareas vinculadas al cuidado del hogar doméstico $u$ otras ejecutadas en su seno, como era el caso de la costura o el bordado, o incluso en la elaboración de remèdes de bonne femme, su espíritu permanecía casi siempre ocioso. Las mujeres, conforme al modelo de "feminidad tradicional», aparte de cumplir con la sagrada misión de ser buenas madres y esposas, debían adoptar una noble fachada para no generar ningún tipo de chismorreo que desacreditara esa inventada condición femenina.

El fenómeno del "qué dirán» se veía reflejado en la vida social de las mujeres burguesas, para quienes las visitas constituían la quintaesencia de su quehacer cotidiano, siendo las apariencias, el «qué dirán», los chismorreos y los "escándalos de pacotilla» su base estructural. Se trataba de la apoteosis de la doble moral, donde se ensalzaba en público lo que se despellejaba en privado, aparte de sublimarse, claro está, envidias y rencores, o jugar a ser lo contrario de lo que realmente se era (Capel Martínez, 1986, p. 268; Núñez Florencio, 1998, p. 119 y p. 122). Además, las mujeres de la alta burguesía y/o de la aristocracia, con toda probabilidad, eran quienes sentían con mayor intensidad el letargo producido por su reclusión dentro de la idealidad creada en torno a su feminidad. Puede que se sintieran perdidas gastando el dinero que les sobrara en compras superfluas o viajes sin interés alguno por su parte, que no sintieran más placer que en esas «mille futilités, qui n'ont aucune valeur», y encontraran la solución en la obra social promovida por la Iglesia, porque, sin duda alguna, como apuntaba el abate Grimaud (1933, p. 136), era la forma más cuidadosa de satisfacer sus gustos y aficiones sin despertar los rumores del «qué dirán», y, por lo tanto, mantener íntegra su condición femenina a ojos de la opinión pública. 


\section{CONCLUSIÓN}

La connotación positiva que los remèdes de bonne femme poseían en su principio, debido a su acepción latina, fue perdiéndose con el paso del tiempo, puesto que las ciencias médicas también iban evolucionando. Además, al ser esta acepción de origen francés, el juego léxico-fonético que en ella se daba, y su inmediato vínculo con las mujeres, hacía que esta adquiriera cierta relevancia en el contexto socio-cultural del país vecino. Desde que se acuñó el término, a finales del siglo XVII, dichos remedios tradicionales fueron en un primer momento exaltados y posteriormente vilipendiados, en el mundo de la ciencia y en la literatura no-científica, pero sin dejar de asociarse con el colectivo femenino. Los saberes pasados de generación en generación, transmitidos sobre todo de madres a hijas por ser estos oriundos del mundo del hogar doméstico, se aplicaban sin cuestionarse el porqué de su uso ni de su efectividad. La ignorancia era la nota dominante en esta dinámica de cesión de un conocimiento que básicamente provenía de las plantas, el cual no tuvo su merecido reconocimiento hasta finales del período decimonónico.

A las mujeres se las apartaba de la Medicina oficial, porque se consideraba que no debían inmiscuirse en el mundo de la ciencia, dado que el sistema dominante así lo había predispuesto. Además, salvo alguna excepción expuesta en este estudio, tampoco se las preparaba para ello. Sin embargo, algunas de estas bonnes femmes elaboraron auténticos manuales médicos de forma autodidacta, presentándolos, pese a todo, con el nombre de remèdes de bonne femme y reafirmando el valor que el saber tradicional llevaba implícito. Se trataba de manuales de medicina preventiva cuyos conocimientos se difundían de un modo sencillo e inteligente entre la población, siendo estos, en consecuencia, mucho más útiles que los voluminosos tratados que ilustres médicos escribían para poder curar lo que podía haberse prevenido.

Pese a estas iniciativas, en la mente del imaginario colectivo, al inaugurarse el pasado sigo, y también a finales del XIX, empezaría a producirse la progresiva devaluación del término bonne femme. Sería este el momento en el que a la mujer instruida en la denominada Medicina tradicional se le otorgaría todo un compendio de nefastos atributos que la alejaron de la imagen de mujer sabia e instruida que tuvo antaño, para acercarla a la despectiva calificación de bruja, privándola de toda credibilidad, no solo en cuanto a los remèdes de bonne femme que difundía, sino a su "palabra de mujer». Así pues, los saberes que en un principio eran propios del mundo de la ciencia y la Medicina, y del respeto por la tradición, terminaron comulgando con los de la magia y la superstición, en función del gradual descrédito de la condición femenina.

\section{NOTAS}

1 Antoine Furetière (1702, p. 882) lo denominaría "vieux terme du Palais» para designar su uso culto.

2 Se refiere al famoso Dictionnaire de la langue française escrito por Émile Littré (1801-1881), el cual fue publicado en Hachette en 1846, siendo una referencia clave desde el punto de vista etimológico durante toda la era decimonónica.

3 Dícese de la devoción por el otro/a antes que por sí mismo/a.

4 De nombre completo François de Salignac de La Mothe-Fénelon.

5 Lo que damos en llamar «feminidad tradicional» es aquella feminidad que se concibe bajo las premisas del discurso patrimonial, donde, según Alain Corbin
(1998), las mujeres eran concebidas como propiedad privada, sobre todo bajo la concepción burguesa de la vida, la cual venía apoyada por la Iglesia, enclave moral, pero también político y económico, a partir del cual se mantenía el orden social.

6 De nombre completo Marie de Rabutin-Chantal, también conocida como Marquesa de Sévigné.

7 Así lo indicaba el Dr. M. Alexandre, médico y profesor de la École préparatoire de Médecine d'Amiens, en su discurso realizado ante la Académie d'Amiens, el 11 de febrero de 1854 , al comentar que el insigne literato francés, en sus obras, atacaba la ciencia al presentarla como una farsa en la que se volcaba ciegamente todo el imaginario colectivo.
8 Entiéndase esta como análoga a la que damos en Ilamar Medicina tradicional.

9 Da fe de ello el hecho de que, en 1926, la Société académique de l'Oise (archéologie, sciences, lettres et arts) celebrara, aunque algo más de tres años después del oficial, el tricentenario del nacimiento de Madame de Sévigné. En el evento en cuestión, el Dr. Leblond, miembro honorífico de dicha asociación, impartió la conferencia titulada «Mme de Sévigné et les remèdes de bonne femme au dix-septième siècle», donde se ensalzaba la actividad de la aristócrata y la importancia que daba a la Medicina tradicional (François, 1926, p. 2).

10 Esta educación pasará a ser obligatoria un año después, en 1882, con la promulgación de la ley Ferry, siendo la edad de 
dicho imperativo la comprendida entre 6 y 13 años (VV. AA., 2013, p. 52).

11 En 1904, en Francia, la mortalidad infantil oscilaba entre unas 130 y 140.000 muertes de niños menores de un año de edad (Frollo, 1904, p. 1)

12 Sirva la utilización del masculino genérico para aludir tanto a mujeres como a hombres.

13 Este es el caso del propio periódico La Croix, quien, desde la década de los años ochenta del siglo XIX hasta principios de la pasada centuria, estuvo anunciando los remèdes de bonne femme dentro de un apartado denominado «économie domestique».

14 En los años previos a este logro, desde 1919, las clases realizadas para las mujeres en la Universidad francesa recibieron el nombre de Hilbert, distinguiéndolas, aunque se tratara del mismo contenido, de los cursos que recibían los hombres (Boyé, 2002, p. 212)

15 Entre las páginas de esta obra podían encontrarse capítulos enteros dedicados a las transfusiones de sangre, la utilización de la hidroterapia para Ilevar a cabo las amputaciones de miembros, las formas de anestesia, el modo de tratar ciertos traumatismos graves, entre otras curas que con toda probabilidad Madeleine D. habría visto practicar en el campo de batalla (Anónimo, $1895-1897$, pp. $138-142$, pp. 1.358 1.383 у рр. $1.407-1.410)$

16 De los múltiples temas que sobre la maternidad fueron abordados en el manual, habría de mencionarse la importancia de las cunas, el modo de vestir a los recién nacidos, la higiene que estos debían recibir, la vacunación, la lactancia o cómo prevenir y afrontar las distintas enfermedades que pudieran contraer, como la diarrea, el cólera infantil, las convulsiones, el «resfriado del cerebro», la oftalmía, entre otras más (Anónimo, 1895-1897, pp. 5-55). En ese compendio de consejos, la lactancia ocupaba un lugar predominante, dado que, todavía en el pasado siglo, los remèdes de bonne femme eran muy escuchados, sin ponerse en entredicho ese ancestral saber popular femenino (G. P., 1919a, p. 3).

17 Entre estas enfermedades se encontraban la histeria, el cáncer de mama, la metritis, etc., así como otras que por aquel entonces se encuadraban dentro de esa categoría, como la menopausia, el embarazo o el parto (Anónimo, 18951897, pp. $158-187$ y pp.1.477-1.509).

18 Así, en el periódico Le Gaulois (1868-), se hablaba de la recuperación de una dama de París, Mme Aubernon de Neuville, quien había sido picada por un insecto venenoso y, gracias a un remède de bonne femme, volvía a su actividad de organizar soirées (Domino, 1890, p. 1).

19 De nombre completo Pierre Alexis, vizconde de Ponson du Terrail.

20 Así lo apuntaba Jean Chateau (1905, p. 87), cirujano dentista de la Facultad de Medicina de Paris, en su obra Un danger menaçant pour la Santé Publique publicada en 1905, al referirse a lo poco considerados que eran los remedios populares para el cuidado de los dientes.

21 Asesinado por Pierre-Napoleón Bonaparte (1815-1881), un pariente de $\mathrm{Na}$ poleón III, a la edad de 21 años. Este suceso trastornó a la opinión pública, y muy especialmente al mundo de la prensa, que encumbró la figura del joven periodista hasta convertirlo en héroe nacional, provocando, a su vez, toda una serie de manifestaciones populares que hicieron tambalear el Imperio napoleónico (Gluckstein, 2011, p. 73).

22 Así lo recalcaba un anuncio publicado en 1914 , en Le Matin, donde podía leerse «Ne désespérez pas !!! La Médicine Végétale, par les sucs et les vitaux des plantes, vous sauvera» (Anónimo, 1914, p. 8).

23 La Croix, en 1937, sostenía este argumento, restando, a su vez, la carga negativa que se les atribuía a los remèdes de bonne femme.

24 Dado que se trataba de una obra que seguía a una anterior escrita por el $\mathrm{Dr}$. Cabanès, y en cierto modo se esperaba desde hacía tiempo, el Journal des débats politiques et littéraires se adelantó a su publicación anunciándola en el mismo momento en que esta se dio por terminada.

25 Autor de la célebre obra Le guide historique de Paris, publicada en 1874 en la editorial Dentu.

26 Tómese como fecha aproximada, ya que, eventualmente, también en 1883 y 1889 , según consta en la Bibliothèque Nationale de France (BNF), se volvió a publicar dicha sección para uno o dos ejemplares.
27 Este autor nada tiene que ver con el escultor francés Jean de Bay (18021862), aunque es probable que este utilizara su nombre como seudónimo.

28 Seudónimo de Marc de Rossiény.

29 Entiéndase como el elemento químico radioactivo.

30 El Comte de Guiche, Armand de Gramont (1637-1673), fue un personaje que gozó de gran popularidad en la Francia de mitad del siglo XVII, ya que era hijo de la sobrina del Cardenal Richelieu (1585-1642). Dicha figura no solo aparece en la obra de Sophie Gay, sino que también la encontramos en otros autores franceses, como Roger de Bussy-Rabutin (1618-1693) y Alexandre Dumas (1802-1870).

31 Enfermedad consistente en una inflamación aguda del tejido celular de los dedos, principalmente de su tercera falange.

32 Según el imaginario colectivo, y muy especialmente en los textos literarios y periodísticos, la razón gobernaba el mundo diurno con una lógica egoísta que se manifestaba dentro de la esfera de lo público, su coherencia determinaba el devenir de la humanidad y las decisiones que esta tomaba tenían un cariz marcadamente masculino. Mientras, el corazón se aliaba de lleno con las mujeres, quedándose todas ellas privadas de la razón, hundidas en una oscura ignorancia mal atribuida, resistiéndose a cumplir aquello que el entendimiento les mandaba, desarrollando, así, la intuición, la imaginación y el sentimiento en el desconocido mundo de lo doméstico (Luengo, 2009, pp. 71-78)

33 En ocasiones, se recurría a los remèdes de bonne femme cuando los médicos no daban resultado alguno (Anónimo, 1828 , p. 3; Villemot, 1869, p. 1)

34 Le Figaro (1826-) comentaba que muchos médicos echaban mano a los remèdes de bonne femme por la única razón de que estos curaban de verdad, sin preguntarse ni siquiera el porqué de ello. En este caso en concreto, se trataba de unas cataplasmas de cebollas blancas para combatir la fiebre mucosa y tifoidea (Paris, 1881, p. 1).

35 Al otro lado de la frontera, el catolicismo se erigió como la voz de la conciencia femenina, dictando a las mujeres no solo el modo de proceder frente al 
mundo que las rodeaba, sino además su forma de pensar y de sentir. Por eso, el diario La Idea consideraba que las mujeres, dado su elevado índice de analfabetismo, "estaban encadenadas a las sotanas de los sacerdotes y al altar de las supersticiones de la Iglesia» (Anónimo, 1931b, p. 3).

36 Ante el desconocimiento del porqué curaban los remedios tradicionales, no eran pocos quienes atribuían sus efectos beneficiosos al propio cielo. Este es el caso de Jean Nesmy (1912, p. 3), quien, en un relato titulado L'Onguent du Pauvre Homme, aparecido en forma de folletín por entre-

\section{BIBLIOGRAFÍA}

Alexandre, A. (1854). Les Médecins. Lecture faite à l'Académie d'Amiens. Dans sa Séance du 11 Février 1854. Amiens: Imprimerie de Duval et Herment.

Anónimo (1828). «Consultation dramatique», Le Figaro, no 270, p. 3.

Anónimo (1892). «Journaux Français de ce matin», Le Matin, no 2.942, p. 2.

Anónimo (1895-1897). Les remèdes de la "Bonne femme». Encyclopédie générale d'hygiène \& de médicine usuelle. Paris: Fayard Frères.

Anónimo (1897). «Paris. Perfidie Féminine», Le petit parisien, $\mathrm{n}=7.582$, p. 3.

Anónimo (1902). "Variétés», Le petit français illustré, s.n., p. 215.

Anónimo (1906). «Au jour le jour. Remèdes de bonne femme», Journal des débats politiques et littéraires, s.n., p. 1.

Anónimo (1914). «Ne désespérez pas !!! La Médicine Végétale, par les sucs et les vitaux des plantes, vous sauvera», Le Matin, no 10.965 , p. 8.

Anónimo (1931a). «Soyez de votre siècle», Le Petit Parisien, no 19.825, p. 5.

Anónimo (1931b). "Una información del diario de Londres, Morning Post», La Idea, nㅇ5, 59. 3.

Anónimo (1937). "Causerie scientifique. Vieux remèdes», La Croix, no 16.603, p. 3.

Anonyme, Un (1892). "Ce qui se passe. Echos de Paris», Le Gaulois, no 3.438, p. 1. gas en Le Gaulois, contaba la historia de un remède de bonne femme, cuya fórmula se desconocía porque había sido inventado por un ángel en tiempos de peste.

37 Yvonne Knibiehler (1996, p. 140) apunta que la educación sexual en Francia cobró definitivamente fuerza a raíz de las mutaciones sociales y culturales que acompañaron a la Troisième République.

38 Así lo apuntaba el novelista Pierre Alexis Ponson du Terrail (1829-1871) (1868, p. 1), en su obra Le Forgeron

Aurigo, F. (1907). La fégatothérapie: méthode vivante enseignée par les lois de la nature. Marseille: Mouillet.

Avermaete, R. (1925). «Le Satyre», L'Humanité, $\mathrm{n}$ ㅇ. 7.819, p. 3.

Barine, A. (1893). "Hors de France. Les remèdes de bonne femme», Journal des débats politiques qui guérissent, s.n., p. 1.

Bazin, R. (1893). «En Province. Société savante», Journal des débats politiques qui guérissent, s.n., p. 2

Bertnay, P. (1903). «La Naufragée», Le Petit Parisien, $\mathrm{n}$ ㅇ 9.861, p. 3.

Boyé, A. (2002). Les femmes dans les mathématiques. En: Hernández González, Miguel (ed.): Proyecto Penélope. El papel de la Historia de la Ciencia en la Enseñanza Secundaria. La Orotava: Fundación Canaria Orotava de Historia de la Ciencia, pp. 206-213.

Boylesve, R. (1909). «Le Grenier», Le Gaulois, no 11.669 , p. 1.

Brunet, L. (1939). "Aux paysans de la Creuse: "Près d'eux "», La Croix, no 17.164 , p. 7.

Cabanès, A. y Barraud, J. (1907). Comment on se soigne aujourd'hui. Remèdes de bonne femme. Paris: A. Maloine Éditeur.

Cabanès, Dr. (1910). "La Fégatothérapie», Le Petit Parisien, no 12.349, p. 1.

Capel Martínez, R. M. (1986). El trabajo y la educación de la mujer en España (19001930). Madrid: Ministerio de Cultura. Instituto de la Mujer. de la Cour-Dieu (1869-1870), al señalar que París disponía de sus propios remèdes de bonne femme como ocurría también con las demás regiones de Francia.

39 Seudónimo de Mme. Charles Ernest Vincens.

40 Apuntaba el redactor científico Henri de Parville (1838-1909) (1884, p. 2), seudónimo de François Henri Peudefer, que los remèdes de bonne femme provenían de viejos manuscritos de recetas y secretos ancestrales.
Chateau, J. (1905). Un danger menaçant pour la Santé Publique. Grenoble: Typographie et lithographie Gabriel Dupont.

Ciseaux, J. (1880). «Journaux et revues», Gil Blas, no 283 , p. 3.

Condamine, Dr. M. de la (1754-1758). Mémoires sur l'inoculation de la petite vérole. Lûs aux Afflemblées publiques de l'Académie Royale des Sciences les 24 Avril 1754 \& 15 Novembre 1758. Paris: Bibliothèque Royale.

Corbetton, A. de (1897). "Chez les autres», La Croix, no 4.414, p. 3.

Corbière, T. (2003). Les Amours jaunes. Paris: Le Livre de Poche, 1873.

Corbin, A. (1998). Le temps, le désir et l'horreur. Essais sur le dix-neuvième siècle. París: Flamarion.

Cordier, F. (1942). "Bons Remèdes de Bonne Femme», Le Petit Parisien, no 23.368, p. 2

Daremberg, G. (1874). «Variétés. Les Médicaments et les Médications», Journal des débats politiques et littéraires, s.n., p. 3.

Domino, U. (1890). «Ce qui se passe. Échos de Paris», Le Gaulois, no 2.734, p. 1.

Ettmüller, Dr. M. (1698). Pratique spéciale de Médecine. Sur les maladies propres des Hommes, des Femmes et des petits Enfants. Lyon: Thomas Amaulry.

Farez, P. (1936). «Feuilleton du Journal des Débats. Causerie médicale. Les plantes qui guérissent», Journal des débats politiques qui guérissent, $\mathrm{n}$ 옹 18. $\mathrm{p}$. 
Fléchier, V. E. (1693). Histoire du cardinal Ximenés. Paris: Jean Anisson.

François, G. (1926). «Les Associations. La Société académique de l'Oise», Journal des débats politiques qui guérissent, $\mathrm{n}$ 55, p. 2.

Frollo, J. (1904). «Les Écoles des Mères», Le Petit Parisien, no 10.012, p. 1.

Furetière, Antoine (1702). Dictionnaire universel, contenant généralement tous les mots français tant vieux que modernes, $\&$ les termes des sciences et des arts. La Haye-Rotterdam: Arnaud et Reinier Leers.

G. P. (1919a). «L'allaitement maternel», La Croix, no 11.143, p. 3.

G. P. (1919b). «Le martyre des mamans», La Croix, no 11.268 , p. 3.

Garrulus, Dr. (1896). Les gaietés de la médicine. Paris: Société d'éditions scientifiques.

Gautier, E. (1913). "Les Miettes de la Science», Le Petit Parisien, no 13.273, p. 5.

Gauthier, J. (1906). «La Passeur de la Moselle», Le Petit Parisien, no 10.789, p. 3.

Gay, S. (1844). "Le Comte de Guiche», La Presse, s.n., p. 3.

Gluckstein, D. (2011). The Paris Commune. A revolution in Democracy. Chicago: Haymarket Books.

Goudard, H. (1938). Près d'eux. Paris: Stock.

Grell, Ch. (2004). «France et Angleterre : I'héritage du Grand Siècle». En Grell, Ch. y Ramière de Fortanier, A. (dirs.), L'Éducation des jeunes filles nobles en Europe. XVII'-XVIII siècles. París: Presses de l'Université Paris-Sorbonne, pp. 9-30.

Grimaud, Charles (1933). Non-mariées. À celles qui s'en vont solitaires.... Paris: Téqui.
Knibiehler, Y. (1996). «L'éducation sexuelle des filles au XX $\mathrm{X}^{\mathrm{e}}$ siècle», Clio. Histoire. Femmes et Sociétés. Le temps des jeunes filles, no 4., pp. 139-160.

Lebel, Dr. André (1858). Monographie des Hémorrhoïdes ou Traité pratique de ces Maladies. Paris: J. B. Bailières et fils.

Leclerq, M. T. (1827-1828). "L'intrigant malencontreux». En: Proverbes dramatiques. Paris: Sautelet, pp. 1-60.

López Castellón, E. (1999). Simbolismo y bohemia: la Francia de Baudelaire. Tres Cantos (Madrid): Akal.

Luengo López, J. (2009). La otra cara de la Bohemia. Entre la subversion y la resignificación identitaria. Castellón de la Plana: Universitat Jaume I.

Malte-Brun, C. (1819). "France. Paris, 13 janvier», Journal des débats politiques et littéraires, s.n., p. 1-3.

Massé, Dr. J. (1861). Encyclopédie de la Santé. Trois maladies réputées incurables. Épilepsie - Dartres - Scrofules. Paris: P. Brunet. Éditeur.

Montifaud, M. de (1890-1891). «Une grève de femme». En: Les joyeuses nouvelles. Paris: B. Simon, pp. 266-323.

Nesmy, J. (1912). «L'Onguent du Pauvre Homme», Le Gaulois, no 12.862, p. 3.

Noir, L. (1890). "Au Village», Le Matin, no 2.458, p. 3.

Núñez Florencio, R. (1998). Tal como éramos. España hace un siglo. Madrid: Espasa.

Paris, J. (1881). "Un conseil par jour», Le Figaro, no 318, p. 1.

Parville, H. (1879). "Revue de sciences», Journal des débats politiques et littéraires, s.n., pp. 2-3.
Parville, H. (1884). "Revue de sciences», Journal des débats politiques et littéraires, s.n., p. 2

Pauliquen, Y. (2006). Mme. de Sévigné et la Médecine du Grand Siècle. París: Odile Jacob.

Pigault-Lebrun (1880). La folie française, une macédonie. Paris: Degorce-Cadot. Éditeur.

Ponson du Terrail, P. A. (1868). "Le Forgeron de la Cour-Dieu», Le petit journal, s.n., p. 1.

Ponson du Terrail, P. A. (1863). "Le Phénol Bobœuf», Le petit journal, $\mathrm{n}$ 응 1.112 , p. 1.

Quitard, P.-M. (1817). Dictionnaire étymologique, historique et anecdotique des proverbes. Paris: Hyppolite Tilliard.

Renard, M. (1935). «Les mousquetaires des halles», Le Petit Parisien, no 21.489 , p. 1

Spronck, M. (1896). «Au jour le jour. L'ami de la bonne femme», Journal des débats politiques qui guérissent, $\mathrm{n}$ ㅇ 336, p. 1.

Strauss, P. (1906). "Hygiène et assistance», Le Petit Parisien, no 10.978, p. 3.

Tailhade, L. (1902). «Santez Anna ar Palud», L'Aurore, no 1.785, p. 1.

Valmont de Bomare, Dr. J. C. (1768). Dictionnaire raisonné universel d'histoire naturelle. Lyon: Bruyset Frères.

Villemot, A. (1869). «La politique d'un bourgeois de Paris», Le Figaro, no 41, p. 1.

VV. AA. (2013). Éducation et système éducatif. Éthique et responsabilité de l'enseignant. París: Hachette. 